\title{
A Desire to Invent New Mediums (A Hatred of Boredom) ${ }^{1}$
}

\author{
KYLE MILLER
}

Syracuse University

This paper posits that what unites us is also what divides us. To continue to invent, develop, and exemplify novel, innovative, and nuanced strategies for producing Form, Space, and Order is an ambition all experimentally minded architects share. Its what enables a narrative of continuous evolution within the discipline of architecture. But the continual reworking of new conceptual support structures for contemporary architecture that do not correspond to the dominant mediums established by previous generations and broader cultural contexts ensures the ruptures between generations of architects that this paper session seeks to mend. This paper tracks the emergence of new conceptual support structures in contemporary architecture and makes a case for continual transformation and divide as the condition that "affiliates individual projects with a possible whole."

In Under Blue Cup, Rosalind Krauss proposes the term technical support as a replacement for the more widely accepted definition of a traditional medium - a substrate such as a canvas with paint or a metal armature that receives plaster. ${ }^{2}$ Technical support refers to acts, artifacts, or concepts that are readily accessible to and associated with broader culture such as animation, PowerPoint, the sound track, the architectural trope of the promenade, and investigative journalism, to name a few. Krauss explores eight examples of artists inventing new technical supports as way to ensure conceptual and aesthetic coherence across their works, which often employ multiple traditional mediums. She posits that the act of claiming these novel, potentially untapped conceptual territories, and surrounding them with a set of conventions regarding their use is akin to inventing a new medium for artistic production.

Among the set of eight examples Krauss provides exists Ed Ruscha and his use of the automobile as a recurrent visual and conceptual thematic for his artwork. Ruscha's fascination with the open road and the vast nothingness of the American West is condensed into his artworks spanning across two decades. For example, in 1963 Ruscha photographed gas stations along Route 66 during road trips between Los Angeles and his hometown of Oklahoma City. The photographs, collectively titled Twentysix Gasoline Stations, were reproduced and compiled in photo books rather than the typical limited edition prints that were popular at the time. ${ }^{3}$ In 1966, Ruscha published Every Building on the Sunset Strip, which amounts to a virtual cruise down Sunset Boulevard in Los Angeles, paying homage to the commercial culture of the Strip. These are just two of many examples where car culture is the conceptual support structure across multiple works executed in the traditional mediums of painting, printmaking, drawing, photography, and film.

Krauss quotes Ruscha to capture an instance of the transition from traditional medium to technical support. Ruscha claimed, "I'm painting on the book covers. I guess I'm just looking for another support. Maybe I'm moving away from the canvas, but I can't predict. I still paint on canvas, but I think there's another shift about to happen somewhere, maybe not so radical, but at least one that I know I will want to stick with." Ruscha is rejecting the traditional medium-the support material that gains legibility based upon its physical properties (for painting, it's the flatness of canvas)-and replaces it with what Krauss calls a new technical support, which enables the artist to discover a rule set which becomes the basis for the medium's specificity. Here, Krauss' specificity is tied to the conventions that the artist must tend to while making use of the medium. This model of specificity differs from the previously dominant model established by art historian Clement Greenburg, one that ties medium specificity to the properties and qualities of the physical substance. ${ }^{4}$

The invention of new mediums was particularly important in the fine arts in the 1970s. The previous decades witnessed the dematerialization of the art object and the triumph of "idea" over artistic merit. Think of Duchamp placing signed urinals in the world's most significant art museums. ${ }^{5}$ With the loss of traditional evaluative criteria and the waning significance of medium specificity, the legibility of the fine arts as disciplined pursuits was fading. Perhaps Ruscha's insistence on inventing a new medium represents a parallel to our contemporary circumstance in architecture-one full of emerging designers inventing new conceptual support structures for their work. And perhaps the arrival of these new conceptual support structures is quite timely given the proclamation that there is no longer a singular discipline of architecture because of the fragmentation of shared mediums and value systems. ${ }^{6}$

Both acknowledging and transcending the traditional mediums of Form, Space, and Order, items such as Bodies, Lines, Profiles, and Rocks emerge as recurrent conceptual supports for a plethora of speculative architectural design projects produced by multiple emerging architecture offices. The proliferation of these new mediums and the variety of output they sponsor enables rule sets to develop around 


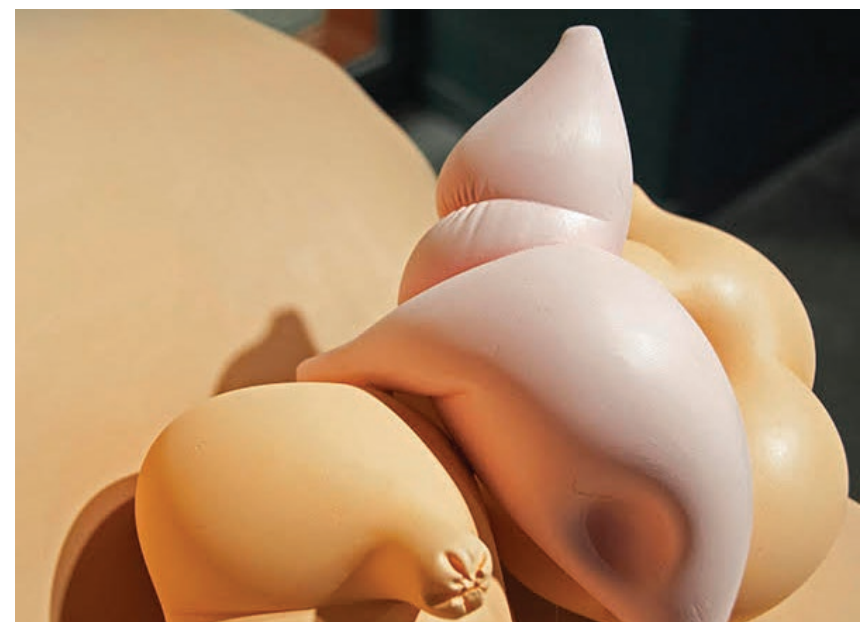

Figure 1. 48 Characters, The LADG, 2013.

them. For example, a designer working Bodies must tend to the particularities of leftover space (spatial relationships), aggregation (part to whole), and resemblance (empty or open signification). Take The LADG's 48 Characters (2013) as an example, where anthropomorphic bricks tumble over one another precariously, simultaneously piling to form wall-like formations and also remaining awkwardly unmatched at their perimeters allowing each "character" to retain its legibility, something the brick traditionally parts ways with the neatly stacked. As an act of speculation, 48 Characters points to new strategies for formal organization and spatial relation. A designer working Profiles must acknowledge the specific qualities of flatness (elevation) and figuration (mass) when manipulating a two-dimensional profile in three-dimensional space. Jennifer Bonner's Domestic Hats (2014) cleverly works profiles in the $\mathrm{x}_{-}, \mathrm{y}^{-}$, and $\mathrm{z}$ - dimension, multiplying the intersection of closed outlines to exaggerate the extruded object-parts in a kaleidoscopic composition of primitive solids.

The desire to find new conceptual support structures-be they Bodies, Lines, Profiles, or Rocks-is what unites one architect to another and a group of experimentally minded architects to their proximate generational precursors. To continue to invent, develop, and exemplify novel, innovative, and nuanced strategies for producing Form, Space, and Order is an ambition all experimentally minded architects share-its what enables a narrative of continuous evolution within the discipline of architecture. But what unites us is also what divides us. Not only do the two examples above provide evidence of the emergence of new mediums and their corresponding specificities, but they also reveal the departure from previous paradigms. 48 Characters celebrates incongruence and lacks formal bravado. Domestic Hats is a compilation of profiles extruded sequentially and discrete, flat elevations. These qualities-incongruence and flatness, in particular-are directly at odds with the ambitions of speculative works that came five to ten years earlier and pursue seamlessness and a lack of frontality.

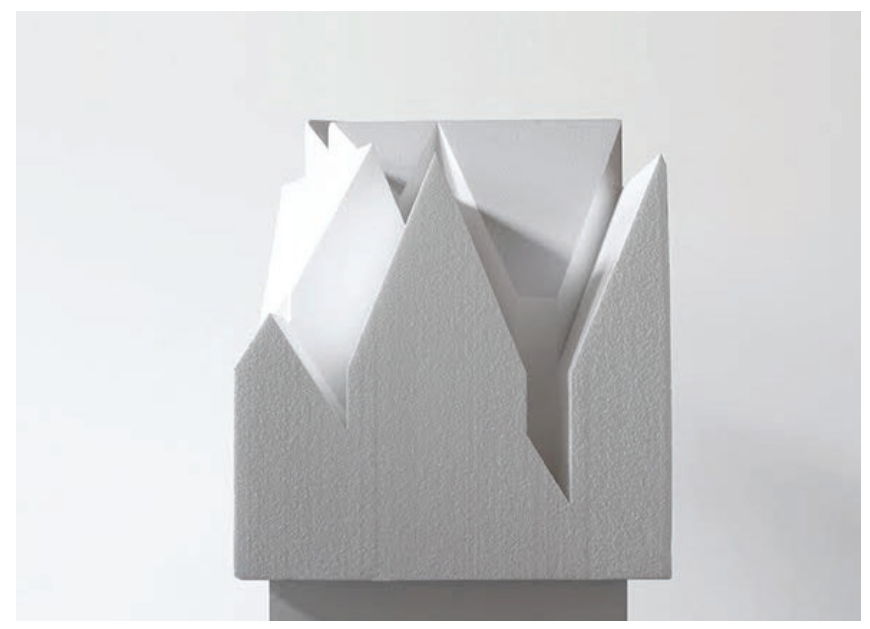

Figure 2. Domestic Hats, MALL, 2014.

Projects such as Pleonasm 4 (2008) from Gage/Clemenceau and Batwing (2008) from Emergent provide clear evidence of these opposing commitments. Representing a set of work that effectively perfects the elegant digital form project-15 years in the making - these projects go to great lengths to produce continuous curvature and maintain fluidity between elements, and were doing so in part to differentiate themselves from experimental work two decades before that pursued fragmentation and heterogeneity - think of work included in MoMA's Deconstructivist Architecture exhibition from 1988. And rather than encouraging audience participation through cognitive association and emphasizing the visual experience as new works do, these digital form projects exemplify and exhibit a precise and expert application and manipulation of technique. Beyond tending to visual experience or indexing modes of becoming, formal and spatial adjacency pursued in the work of the newest generation of emerging practices replaces formal and spatial continuity that dominated the works of the previous generation. The particular strategies both groups develop to work on the traditional mediums of Form, Space, and Order produce more nuanced conceptual support structures that reveal the generational divide.

We should not be surprised that such divisions exist; nor should we resist the notion of inter- and intra-generational divides. In the introduction to Practice - Architecture, Technique and Representation, Stan Allen acknowledges the likelihood and expected recurrence of such divides. While recalling De Certeau's walker in the city, Allen reminds us that control exercised by any architectural regime can never be total. He claims that resistance will always find other ways around or through constraints imposed from the outside and that there will always exist fissures and cracks in existing frameworks that enable tactical reworkings. In the context of this essay, these tactical reworkings take the form of new mediums for contemporary architecture that do not correspond to the dominant conceptual support structures established by previous generations and broader cultural contexts. 
While its ambitious and admirable to scrutinize today's interand intra-generational pluralisms, it's ultimately an impossible task to identify robust and continuously coherent "shared underpinnings" within and across decades of critical practice. For the discipline of architecture to evolve, the continual reworking of conceptual support structures necessitates the chasms between generations of architects that this session seeks to mend. A topic for another discussion, but not to be underestimated in the context of this essay is the impact that broader political, cultural, social, economical, and other circumstances have on the manner in which architects place themselves in the world. It's no surprise that the heroism, confidence, and bravado that architecture portrayed post9/11 have been replaced by the light-heartedness, humility, open-endedness, so-called indifference, and even cynicism after the financial crash and during the Trump presidency. Shared experiences tend to rally large groups of people in their formative years around a small set of themes and topics that their works are directly or indirectly attached to. Think of the legacy left by early speculative acts created by many of the post-' 68 architects-Thom Mayne, Bernard Tschumi, and Rem Koolhaas were all born in 1944, all 24 years old in 1968.

In real-time, while the cracks may emerge slowly, hindsight presents them as abrupt ruptures with clear, discrete, and unique identities. In an attempt to temporarily reverse the abruptness of these divides, this essay will conclude with a continuous, provisional, and incomplete list of recurring conceptual support structures from 1988 to 2018: Fragments, Segments, Ruptures, Dislocations, Folds, Creases, Curves, Cusps, Blobs, Forces, Fields, Knots, Animation, Gradients, Performance, Swarms, Systems, Sensations, Fur, Tattoos, Posture, Volumes, Objects, Character, Narrative, Bodies, Figure, Profiles, Stacks, Details, Contracts, and Specifications. Whatever comes next will ensure the dissolution of the novelty witnessed today and the emergence of new conceptual support structures. Around these new mediums, architects will develop new specificities that introduce and convene unprecedented or refreshed techniques, strategies, qualities and effects... only to be resolved, made commonplace, institutionalized, and overtaken; again and again and again.

\section{ENDNOTES}

1 During the celebration of his 90th birthday, Philip Johnson addresses the numerous quick changes in stylistic pursuits that marked his career. He concludes his remarks by admitting a retroactive lack of understanding of the avant-garde as a mere "frantic search for novelty." Johnson's pursuit of the new corresponds to... "A desire to be famous and hatred of boredom. Period." Nathanial Coleman, Utopias and Architecture (New York: Routledge, 2005), 63.

2 Rosalind Krauss, Under Blue Cup (Cambridge, MA: The MIT Press, 2011), 18-19.

3 Edward Ruscha, Standard Station, 1966, artwork, accessed September 24, 2018. https://www.moma.org/collection/works/76637.

4 Krauss, Under Blue Cup, 6-7, 19.

5 Krauss, Under Blue Cup, 20.

6 Michael Meredith, “P.M.S.A.” in Everything All At Once (New York: Princeton Architectural Press, 2013), 171-172. 